\title{
Limitation of Liver tumor promoting properties of butylated hydroxytoluene in non- transgenic C57BL6 black mouse
}

\author{
Elalfy M. Mahmoud ${ }^{1^{*}}$ \\ ${ }^{1}$ Forensic medicine and toxicology department Faculty of Veterinary medicine, Mansoura University, Egypt \\ Received: 28 August 2016 /Accepted: 8 October 2016 \\ *Corresponding author: mahmoudelalfy@mans.edu.eg
}

\begin{abstract}
It was reported previously that butylated hydroxytoluene (BHT) had tumor promoting properties on c-myc transgenic mouse model of liver and lung cancer. To better understand limitation of BHT inducing liver tumor, the promoter activity of BHT in non-transgenic mouse C57BL6 model of liver cancer of short term toxicity was investigated. 40 male mice C57BL6 were divided into 5 groups; first group received corn oil, $2^{\text {nd }}$ group treated with single dose of $100 \mathrm{mg} / \mathrm{kg}$ of diethylnitrisamine, $3^{\text {rd }} \cdot 4^{\text {th }}$ and $5^{\text {th }}$ group treated with single dose of $100 \mathrm{mg} / \mathrm{kg}$ of diethylnitrisamine followed by BHT at doses of 100, 200 and $300 \mathrm{mg} / \mathrm{kg}$ respectively twice per week for 32 weeks. Liver to body weight ratio was increased non-significantly in all treated groups in particular at dose of $300 \mathrm{mg} / \mathrm{kg}$ of BHT when compared with control group. Furthermore, butylated hydroxytoluene at the highest dose increased significantly $(\leq 0.05)$ liver transaminase enzymes, alkaline phosphatase, BUN, cholesterol and glucose level when compared with group 2 treated only with DEN or control group. At 32 weeks, Diethylnitrisamine at dose of $100 \mathrm{mg} / \mathrm{kg}$ induced liver dysplasia while BHT fail to promote conversion of liver dysplasia to ultimate unicellular or focal liver tumor. Notably BHT enhanced leukocytic infiltration and dysplasia of primary pulmonary cell at dose of $300 \mathrm{mg} / \mathrm{kg}$ in histopathology examination. Moreover, on conclusion BHT had no promoting tumor activity in wild mice but butylated hydroxytoluene consider a hazardous chemical for liver and lung tissue at high dose.
\end{abstract}

Keywords: BHT, DEN, Liver, Lung, Dysplasia, C57BL6 Black Mouse.

\section{Introduction}

The population of Egypt has a heavy incidence of liver disease, mostly due to chronic infection with hepatitis C and B virus. Since the liver offers a very important site for detoxification of xenobiotic, the use of preservatives agents offers potential risk factors for tumor promotion

Primary liver cancer has been reported as the fifth most common cause of cancer and the fourth most common cause of cancer mortality all over the world. One of the principal subtypes of liver cancer is hepatocellular carcinoma, which constitutes a major cancer incidence and mortality (Ibrahim and Nassar, 2008)

Butylated hydroxytoluene (BHT) is one of the most commonly used preservative in foods containing fats and in food packaging and other food contact applications, drugs, cosmetics, and animal feeds to prevent oxygen-induced lipid peroxidation. Moreover, 2,6-Di-tert-butyl-4methylphenol (BHT), 2-Tert-butyl-4- 
methoxyphenol (BHA), and 2,4,6-Tri-tertbutylphenol are used alone or in combination frequently as anti-inflammatory or in molar ration and pharmaceutical as antioxidant (Murakami et al., 2015)

In a two-stage model using urethane as the initiator, although up to five successful doses of BHT were able to exert continued enhancing effects in terms of adenoma yield and no increment was evident with further treatments. The data overall indicate that a rasH2/BHT model with five weekly administrations of BHT at a dose of $400 \mathrm{mg} / \mathrm{kg}$ is most efficacious Umemura et al. (2002).

Moreover, Hueper et al., (2012) found that BHT enhanced large dysplastic nodules on c-myc transgenic mouse model of liver cancer at age of 8.5 month detected by pet/ct imaging techniques. Additionally, Bauer et al., 2016 investigated role of BHT promotion of lung cancer in epiregulin transgenic mouse model.

Carcinogenic tests of BHT have been carried out in various ranging from the ames test to cell transformation procedures to in vivo assays. These adverse effects are probably mediated by metabolites of BHT, rather than by BHT itself Malkinson, (1983). Additionally, BHTOOH is a metabolized form of BHT in the skin to several reactive species, including both free radical, electrophilic quinone methide that has been a role in skin tumor promotion. Tumor promotion activity by BHTOOH was need formation of an electrophilic quinone methide (Guyton et al., 1994).

While there were a few studies on humans, with most of these studies just identifying the metabolic products of BHT. Because of the lack of reported toxic effects to human since its wide use in 1954, BHT was used by GRAS (Generally Recognized as Safe) and by the FDA (food and drug administration ) at a level not to exceed $0.5 \mathrm{mg} / \mathrm{kg}$ B. wt./day or $0.02 \mathrm{ppm}$ in foods. According to this regulation, authorities in most countries still add BHT to foods and drugs (Babich, 1982 and FASEB, 1977).

Liver tumor promoting activity of butylated hydroxytoluene (BHT) sill controversial. Witschi, (1981, 1986) also suggested that butylated hydroxytoluene (BHT) had dual promoting and protective roles in occurrence of tumour formation but strain differences, the effect upon various carcinogens, paradoxical dose responses and mechanisms of action remain major questions in the toxicology of BHT.
Inconsistent, butylated hydroxytoluene (BHT) failed to induce biologically significant increases in cellular proliferation in the liver, thyroid gland and urinary bladder on feeding to young adult Wistar rats (Lok et al., 1995). Nevertheless, it had been reported to enhance the volume of liver tumor when fed to rats or mice that developed an appreciable background incidence of these tumors without treatment (Hueper et al., 2012).

Notably, Iverson (1995) found that the neoplastic effects of BHA and BHT was observed at very high dietary levels only at defective immune system. The single intraperitoneal injection of butylated hydroxytoluene at dose of $60 \mathrm{mg} / \mathrm{kg}$ body weight resulted within a few hours in a strong increase in nuclear DNA activity in the liver, and lungs of male rats Vanyushin et al. (1998).

The aim of this study to investigate the tumor promoting activity of butylated hydroxytoluene in wild mouse model for short term of toxicity of initiation-promotion type of carcinogenesis.

\section{Materials and methods}

\section{Laboratory animals, transgenicity and treatment}

40 male mice C57BL6 were divided into 5 groups; first group received corn oil, $2^{\text {nd }}$ group treated with single dose of $100 \mathrm{mg} / \mathrm{kg}$ of diethylnitrisamine, $3^{\text {rd }} \cdot 4^{\text {th }}$ and $5^{\text {th }}$ group treated with single dose of $100 \mathrm{mg} / \mathrm{kg}$ of diethylnitrisamine followed by BHT at doses of 100,200 and $300 \mathrm{mg} / \mathrm{kg}$ respectively twice per week for 32 weeks

\section{Sample collection and preparation}

40 Mice were anaesthetized by intraperitoneal injection of over dose of farcopental and sacrificed at the age of 32 weeks. Blood sample was collected from all groups for separation of serum. All organs weight was recorded. Upon anatomical preparation liver and lung tissue was preserved in buffered formalin $10 \%$. Paraffin blocks were prepared and sectioned into $5 \mathrm{~mm}$ thick slices and stained with hematoxylin and eosin ( $\mathrm{H}$ and $\mathrm{E})$. Frozen liver tissue was kept at liquid nitrogen (Carson and Freida, 1990). 


\section{Blood}

Blood was collected from each mice in a centrifuge tube and placed at room temperature for 20 min. Serum was then separated by centrifugation at $3,000 \mathrm{rpm}$ for $20 \mathrm{~min}$. Serum sample was divided into aliquots, one for determination of serum alanine transaminase (ALT) and serum aspartate transaminase (AST) (Reitman and Frankel (1957), serum alkaline phosphatase (ALP) (Kind and King, (1954), serum glucose (Kaplan, 1984), serum urea concentration (Patton and Crouch (1977) and serum cholesterol (Naito, H. K. and Kaplan, A. ,1984).

\section{Statistical analysis}

Data obtained in this study were statistically analyzed for variance (ANOVA), and least significant difference (LSD) as described by Snedecor et al. (1989).

\section{Results}

There was little increase in body weight especially after treatment but at 32 weeks. Liver weight and liver weight to body weight ratio was increased in mice treated by BHT when compared to control group. (Fig.1)
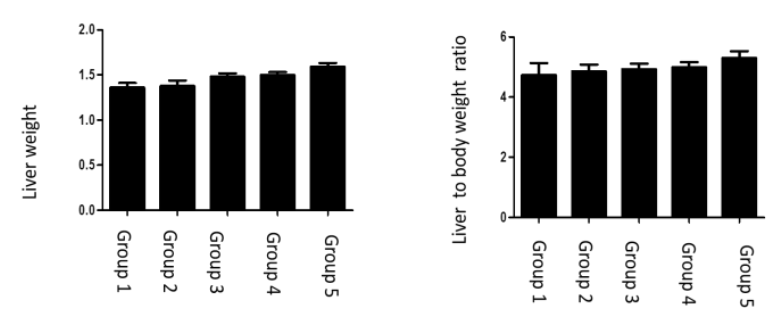

Fig 1. Showed liver weight and liver weight to body weight ratio was increased in mice treated by BHT especially on group 5 treated with single dose DEN followed by $300 \mathrm{mg} / \mathrm{kg}$ of BHT when compared to control group.

It was noticed that group 2 treated only with single dose of DEN increased significantly liver enzymes such as AST, ALT and ALP, cholesterol and BUN. But group 2 treated only with single dose of DEN was reduced glucose level significantly when compared with control group. Moreover, only BHT at dose of $300 \mathrm{mg} / \mathrm{kg}$ increased significantly $(\leq 0.05)$ liver enzymes such as AST, ALT and ALP and BUN (Table 1).

Table 1 showed level of liver enzymes and biochemicals alteration in various groups treated with diethylnitrisamine or both diethylnitrosamine and BHT

\begin{tabular}{|l|l|l|l|l|l|l|}
\hline & \multicolumn{1}{|c|}{$\begin{array}{c}\text { AST } \\
\mathbf{u} / \mathbf{1 0 0 m l}\end{array}$} & $\begin{array}{c}\text { ALT } \\
\mathbf{u} / \mathbf{l}\end{array}$ & $\begin{array}{c}\text { ALP } \\
\mathbf{u} / \mathbf{l}\end{array}$ & $\begin{array}{c}\text { BUN } \\
\mathbf{m g} / \mathbf{d l}\end{array}$ & $\begin{array}{c}\text { Cholesterol } \\
\mathbf{m g} / \mathbf{d l}\end{array}$ & $\begin{array}{c}\text { Glucose } \\
\mathbf{m g} / \mathbf{d l}\end{array}$ \\
\hline Group 1 & $35.75 \pm 1.2$ & $51.2 \pm 1.4$ & $175.4 \pm 3.4$ & $2.03 \pm 0.03$ & $93.11 \pm 2.1$ & $172.9 \pm 3$. \\
\hline Group 2 & $136.6 \pm 2.2^{\mathrm{a}}$ & $178 \pm 2.2^{\mathrm{a}}$ & $211 \pm 3,5^{\mathrm{a}}$ & $2.89 \pm 0.01^{\mathrm{a}}$ & $98.8 \pm 2.3$ & $115^{\mathrm{b}} \pm 4.2$ \\
\hline Group 3 & $141 \pm 3.2^{\mathrm{a}}$ & $179 \pm 3.4^{\mathrm{a}}$ & $213 \pm 3.9^{\mathrm{a}}$ & $3.2 \pm 0.1^{\mathrm{a}}$ & $103.4 \pm 3.2$ & $173.3^{\mathrm{a}} \pm 3.6$ \\
\hline Group 4 & $155.6 \pm 3.3^{\mathrm{a}}$ & $179.8 \pm 2,8^{\mathrm{a}}$ & $213.8 \pm 4^{\mathrm{a}}$ & $3.3 \pm 0.2^{\mathrm{a}}$ & $103.7 \pm 4.2$ & $176,3^{\mathrm{a}} \pm 3.4$ \\
\hline Group 5 & $178 \pm 4.2^{\mathrm{b}}$ & $200.8 \pm 3,5^{\mathrm{b}}$ & $226.4 \pm 3.4^{\mathrm{b}}$ & $3.8 \pm 0.04^{\mathrm{b}}$ & $117.2^{\mathrm{a}} \pm 3.1$ & $186.3^{\mathrm{a}} \pm 5.1$ \\
\hline
\end{tabular}

\section{A,b.c significant at $\mathrm{P} \leq 0.05$}

Notably, Liver of group 2 received only DEN showed apoptotic body and dysplasia of hepatocytes indicated by enlarged nuclei with eosinophilic inclusions and dysplasia of hepatocytes with atypic nucleus. BHT at doses of 100 and $200 \mathrm{mg} / \mathrm{kg}$ showed no difference than group 2 which received DEN. Additionally, BHT at doses of $300 \mathrm{mg} / \mathrm{kg}$ showed severe dysplasia of hepatocytes with atypic nucleus and Lung shown dysplasia of macrophages and neutrophils infiltrating alveoli with the presence of perivascular lymphocytes infiltrating alveoli (Fig. 2). a
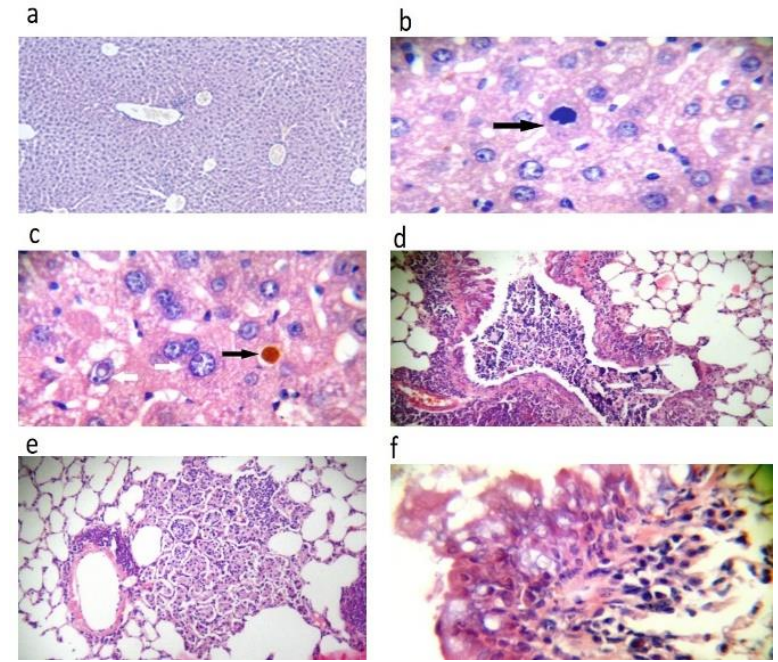

Fig 2: Histopathological examination revealed that BHT fail to induce liver tumor 
a Liver showed normal parenchyma

b Liver showed apoptotic body and dysplasia of hepatocytes indicated by enlarged nuclei with eosinophilic inclusions

c: Liver showed dysplasia of hepatocytes with atypic nucleus

d: Lung showed dysplasia of macrophages and neutrophils infiltrating alveoli with the presence of perivascular lymphocytes infiltration

e: Lung showed leukocytic infiltration in bronchial lumen with dysplasia of bronchial epithelium and peribronchial lymphoid hyperplasia

f: High power of e to show dysplasia of bronchial epithelium

\section{Discussion}

BHT is used extensively in food and drug preservation and as anti-inflammatory agent (Murakami et al., 2015).

There is no detectable liver tumor promoting agent induce alone liver tumor in human. While there were a few studies on the toxicity of BHT to humans with most of these studies just identifying the adverse effect of metabolic products of BHT (Babich, 1982). Moreover, according previous safety studies on BHT, the GRAS (Generally Recognized as Safe) and FDA still approved BHT at a level not to exceed $0.5 \mathrm{mg} / \mathrm{kg}$ body $\mathrm{wt} /$ day or $0.02 \mathrm{ppm}$ in foods (FASEB, 1977).

It was mentioned previously, that BHT could increase liver tumor volume in transgenic mouse model of liver cancer (Hueper et al., 2012). but in the present study, we investigated the tumor promoter activity of BHT in non-transgenic mice was clarified by biochemical and histopathology analysis.

In the present study, liver weight and liver weight to body weight ratio was only significantly increased due to effect of BHT toxicity immediately after treatment when compared to control mice while there was no difference at successful doses at end of treatment.

In the current study, DEN increased significantly liver enzymes such as AST, ALT and ALP and BUN when compared with control group. This result agree with Ibrahim and Nassar (2008) who found that NDEA significantly disturbed liver functions and most of the aforementioned indices. Moreover, only BHT at dose of 300 $\mathrm{mg} / \mathrm{kg}$ increased significantly liver enzymes such as AST, ALT and ALP and BUN when compared with group 2 received only DEN or control group. These result agree with Mizutani et al., 1982) who found that BHT hepatotoxicity was evidence by increase GPT activity and centrilobular necrosis of hepatocytes.

Histopathological examination revealed that BHT at doses of $300 \mathrm{mg} / \mathrm{kg}$ showed severe dysplasia of hepatocytes with atypic nucleus. This result confirm that there is no incidence of liver tumor in all mice given both DEN and BHT for 32 weeks. This result agree with Inai et al., (1988) who reported that there was no incidence of liver tumor due BHT treatment in mice of both sexes. Additionally, this result agree with Shirai et al. (1982) who found that there was no carcinogenicity of butylated hydroxytoluene on long-term administration to $\mathrm{B} 6 \mathrm{C} 3 \mathrm{~F} 1$ mice.

In our study, BHT at doses of $300 \mathrm{mg} / \mathrm{kg}$ showed dysplasia of macrophages and neutrophils infiltrating alveoli with the presence of perivascular lymphocytes infiltrating alveoli. This result agree with Witschi (1983) who found that there was no evidence to show that BHT would enhance tumor development in lung tissue except in animals treated with sub-carcinogenic doses of an initiating compound as urethane.

On conclusion, BHT had no tumor promoting properties as higher doses fail to promote hepatocyte dysplasia ultimate liver tumour but considered as a hepatotoxic substance at high doses for chronic exposures.

\section{References}

Babich H. (1982): Butylated Hydroxytoluene (BHT): A Review environmental research 29, 1-29

Bauer AK1, Velmurugan K1, Xiong KN1, Alexander CM1, Xiong J1, Brooks R (2016): Epiregulin is required for lung tumor promotion in a murine twostage carcinogenesis model. Mol Carcinog. Feb 19. doi: $10.1002 / \mathrm{mc} .22475$

Carson, H.T. and Freida, L. (1990): pathological technique in Histotechnology book. American society clinical pathologist pages 4-30

FASEB (1973): Evaluation of the health aspects of butylated hydroxytoluene as a food ingredient. NatlTechnical Info Service \#PB-259917. 19 pp.

FASEB Report (1977): Butylated hydroxytoluene. Use restrictions. Federal Register 42:27603-27608.

Guyton Kathryn Z., Dolan Patrick M. and Kensler2 Thomas W. (1994): Quinone methide mediates in vitro induction of ornithine decarboxylase by the tumor promoter butylated hydroxytoluene hydroperoxide Carcmogenesis Vol.15 no.5 pp.817821.

Hueper k., Elalfy M., Laenger F., Halter R., Rodt T., Galanski M., and Borlak J. (2012): pet/ct imaging 
of c-myc transgenic mice identifyies the genotoxic n-nitroso-diethylnitrosamine as carcinogen in short term carcinogenicity.

Ibrahim Safinaz S. and Nassar Noha N. (2008): Diallyl sulfide protects against $\mathrm{N}$-nitrosodiethylamine induced liver tumorigenesis: Role of aldose reductase World J Gastroenterol October 28; 14(40): 6145-6153.

Inai Kouki, Komuke Toshihiro, Namau Shigeru, Takemoto Tsuyoshi,Kou Eihaku Nishina Hajime , Fujihara Megumu, Yonemara Shujl, Suehiro Shinichi,Tsuya, Horiuchi Kenji And Tokuoka Shoji (1988): Hepatocellular Tumorgenicity Of Butylated Hydroxytoluene Administered orally to B6C3F1 mice. Jpn. J. cancer research (gann) 79, 4958.

Kaplan, L. A. (1984): A colorimetric method for determination of glucose. Clin Chem the C.V. Mosby CO. St Louis. Toronto. Princeton 10321036.

Kind, P.R.N. and King, E.G. (1954): Estimation of plasma alkaline phosphatase by determination of hydrolysed phenol with amino-antipyrin. J. Clin. Pathol. 7:322.

Lok E., Mehta R., Laver Jee, G., Nera E.A., McMullen E. and Clayson D.B. (1995): The effect of butylated hydroxytoluene on the growth of enzyme altered foci in male Fischer 344 rat liver tissue Carcinogenesis 16 (5) 1071-1078,

Malkinson Alvin M. (1983): Putative Mutagens and Carcinogens in Foods 111. Butylated Hydroxytoluene (BHT). Environmental Mutagenesis 5353-362.

Mizutani Tamio, Nomura Haruko, Kazuo Nakanishi, and Setsuya Fuji-Ia (1987): Hepatotoxicity of Butylated Hydroxytoluene and Its Analogs in Mice Toxicology And Applied Pharmacology 87, 166176

Murakami Y,kawata A, katayama T, fujisaw S (2015): antiinflmatory of activity of the antioxidant 2-tertbutyl-methoxyphenol(BHA) , 2,6 ditert--butylmethoxyphenol(BHT) and 2,4,6 tritert- butylphenol (TBP) invivo. ; 29(2:197-205)
Naito, H. K. and Kaplan, A. (1984): A colorimetric method for determination of Cholesterol. Clin Chem the C.V. Mosby CO. St Louis. Toronto. Princeton1194- 11206.

Patton, C. J. and Crouch, S. R. (1977): A colorimetric method for determination of serum urea Anal. Chem., 49:464-469.

Reitman S. and Frankel S. A mer (1957): A colorimetric method for determination of serum glutamic oxalacetic and glutamic pyruvic transaminase J. Clin. Pathol. 28:56

Shirai T, Hagiwara A, Kurata Y, Shibata M, Fukushima S, Ito $\mathrm{N}$ (1982): Lack of carcinogenicity of butylated hydroxytoluene on long-term administration to B6C3F1 mice. Food Chem Toxicol. Dec; 20(6):861-5.

Snedecor, George W. and Cochran, William G. (1989): Statistical Methods, Eighth Edition, Iowa State University Press.

Umemura T, Kodama Y, Hioki K, Nomura T, Nishikawa A, Hirose M, Kurokawa Y. (2002): The mouse rasH2/BHT model as an in vivo rapid assay for lung carcinogens. Jpn J Cancer Res. 2002 Aug; 93(8):861-6.

United States International Trade Commission (1977): Synthetic organic chemicals-United States production and sales, 1976. USITC Publication 833, U.S. Government Printing Office, Washington, D.C., p. 299.

Vanyushin BF, Lopatina NG, Wise CK, Fullerton FR, Poirier LA. (1998): Butylated hydroxytoluene modulates DNA methylation in rats. Eur J Biochem. 15;256 (3):518-27.

Witschi H. P. (1983): Promotion of Lung Tumors in Mice. Environmental Health Perspectives 50, 267273,

Witschi, H. P. (1986): Enhanced tumour development by butylated hydroxytoluene (BHT) in the liver, lung and gastro-intestinal tract. Food Chem. Toxicol. 24, 1127-1130.

Witschi, H. P., Hakkinen, P. J., and Kehrer, J. P. (1981): Modification of lung tumor development in $\mathrm{A} / \mathrm{J}$ mice. Toxicology. 21, 37-45. 


\section{الملخص العربي}

عنوان البحث: قصور تنشيط سرطان الكبد لمادة البيتوليد هيدروكسي تولوين في الجرزان السوداء

محمود محمد الألفي 1

1 كليه الطب البيطري - جامعه المنصورة

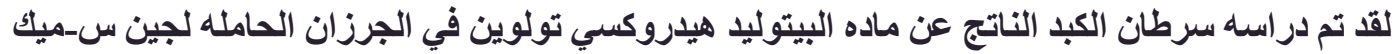

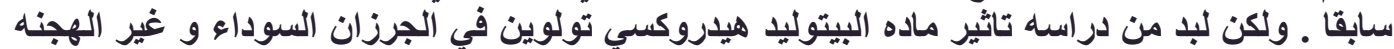

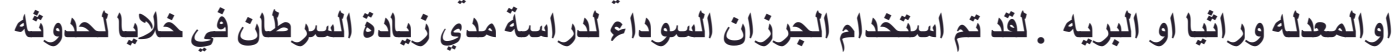

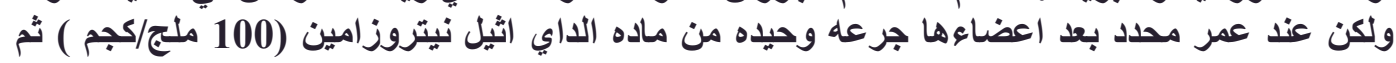

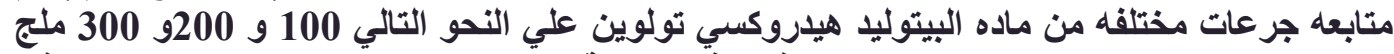

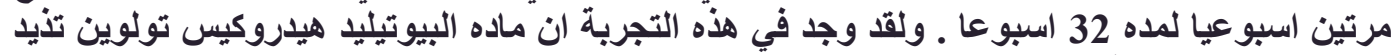

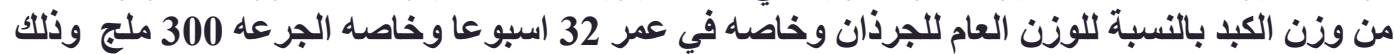

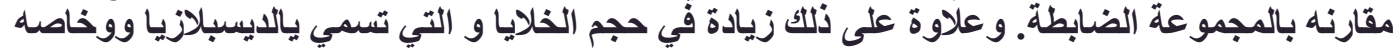

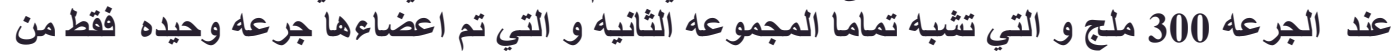

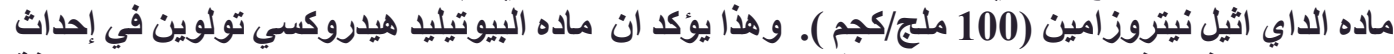

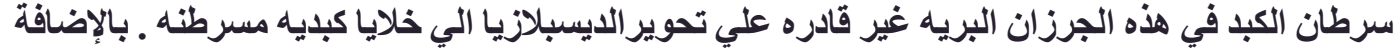

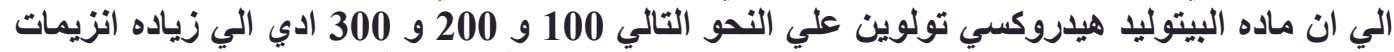

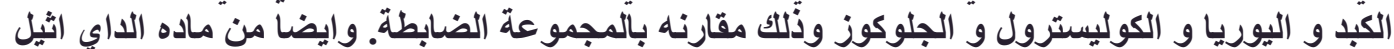

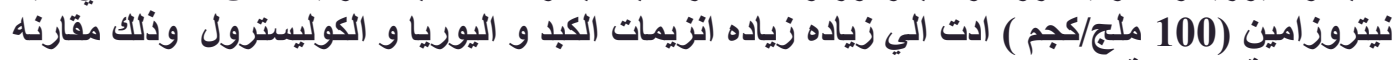

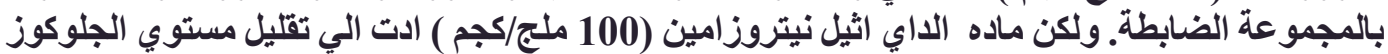

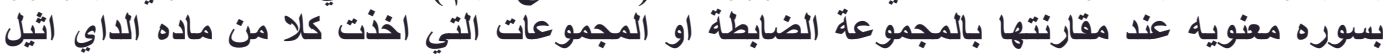

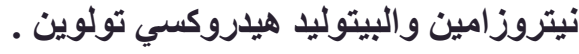

